\title{
AC 2007-233: CAN A MEDIA STRATEGY BE AN EFFECTIVE RECRUITMENT AND RETENTION TOOL FOR WOMEN IN ENGINEERING AND TECHNOLOGY? A PILOT STUDY
}

Mara Wasburn, Purdue University 


\title{
Can a Media Strategy be an Effective Recruitment and Retention Tool for Women in Engineering and Technology? A Pilot Study
}

\begin{abstract}
Despite the fact that many Western nations face a critical shortage of skilled professionals in science, technology, engineering, and mathematics (STEM) and despite abundant job opportunities in STEM disciplines, few women still prepare themselves for careers in these fields. Recently, there have been suggestions that new media programming, such as television dramas with women engineers, computer technicians, and/or engineers in leading roles, might help attract more women to these fields. This paper identifies a theoretical rationale for a media centered strategy. It involves using the mass media to create a more positive understanding of women in these professions. It then describes a pilot study that utilized a national sample. Data from that survey suggest that a media-centered approach might have some success in producing greater interest among women in pursuing certain STEM careers.
\end{abstract}

\section{Introduction}

It is commonly accepted that part of the solution to the increasing problem of the shortage of well trained technical personnel in all advanced industrial nations involves attracting considerably more women to careers in STEM disciplines. Approximately half the potential STEM talent pool consists of women. In the United States, there is still a great deal of occupational segregation by sex. Although women constitute 46 percent of the labor force, less than a quarter of the scientists and engineers in the country are women. ${ }^{1}$ International comparisons of occupational segregation are difficult because nations seldom use comparable coding systems. ${ }^{2}$ However, such data as are available indicate not only the existence of such a gendered division of labor throughout Western Europe, but also the likelihood of its persistence. For example, while half of all university students in Germany are women, women represent only 34 percent of all students in the natural sciences and 19 percent of all students in engineering. ${ }^{3}$ Similarly, men were found to be over represented among computer science graduates in all 21 industrial nations considered in a recent study. In the United States, the "male over representation factor" is 2.10, in the United Kingdom 3.10, in France 4.57, and in Germany $5.58 .^{4}$

In 2000, a United States government commission was charged with developing strategies to attract more women and minorities in STEM careers. The commission reported to the Committee on Science of the House of Representatives that significant barriers to these goals persist (Committee on Science, 2000). Such deterrents range from differing male/female attitudes toward science and technology that begin to diverge as early as elementary and middle school, to the absence of women faculty, mentors, and fellow students in college and university classrooms that create a "chilly climate for women" in these areas. 2,5

A 2003 United States National Science Foundation publication ${ }^{6}$ described 211 ongoing projects in the country designed to attract and retain women and in STEM courses. More than $\$ 90$ million had already been poured into these projects. Given the proliferation of such efforts, some measurable effect on the entry and persistence of women in these professions should be 
expected. However, studies indicate no substantial gains. ${ }^{7,8}$ In fact, much of the progress that women have made in these areas has stalled or eroded. ${ }^{9}$ Such findings indicate the importance of developing additional new strategies for attracting more women into STEM programs. One such approach, which is the focus of this paper, involves using the mass media to create a more positive understanding of women in these professions.

This approach was the topic of a seminar entitled "Women in Science and Engineering, and TV Drama: Sex, Lives, and Videotape" held in November 2004 in London's Institution of Electrical Engineers. The event was organized by the Public Awareness of Science and Engineering (PAWS) Drama Fund and was supported by six of the United Kingdom's leading science, engineering, and technology organizations. The seminar brought together scientists, engineers, and television drama producers and writers. Its goal was to offer recommendations for helping and encouraging the media to present more well-rounded, up-to-date, and attractive images of women in STEM careers through the development of new programming such as science-based television dramas with women in leading roles.

\section{Theoretical Rationale for a Media Strategy}

The international feminist movement in the 1960s helped advance the idea that cultural understandings of gender roles are socially constructed and have to do with ideology and power rather than being "natural." The basic theoretical insight that our understanding and experience of the world of everyday life is socially constructed was first fully articulated in the early 1930s by German philosopher Alfred Schutz ${ }^{10}$ who sought to develop a sociological variant of phenomenology. The work gained considerable influence in the United States when it appeared in English in 1967. This was one year after Peter Berger and Thomas Luckmann's theoretically similar study "The Social Construction of Reality" "11 had gained the attention of American social scientists. The publication of the two studies corresponded with the height of feminist activity. For example, the National Organization of Women was founded in 1966.

Schutz views all of us as carrying in our minds a "stock of knowledge of physical things and fellow citizens, of social collections and artifacts, including cultural objects"9 (p. 81). This stock of knowledge provides a frame of reference or orientation with which we can interpret objects and events as we conduct our everyday lives. Additionally, the objects and events of the world have no inherent or universal meaning apart from this imposed framework.

It is Schutz's contention that we assume other members of our society generally share our stock of knowledge and will experience the world in the same way we do. We assume that others will see the world as being made up of the same types of objects and events, that these objects and events will have the same meaning for them, and that they will respond to them in ways they themselves have learned are appropriate.

In the 1970s, George Gerbner ${ }^{12}$ introduced a major constructionist theory focusing on the influence of mediated reality on social behavior. He was concerned with how the vast amount of violence portrayed on American television exaggerated the fears people have about encountering violence in their own neighborhoods. Later developed as cultivation theory, the approach asserts that, at least among heavy users, television produces a "mainstreaming" effect whereby differences in beliefs in otherwise heterogeneous populations are muted. Heavy television 
viewers internalize many of the perspectives on the social world presented by television. Such influence occurs as a result of continual and lengthy exposure to television in general, not just exposure to individual programs or genres.

Succeeding generations also learn meanings of the social order, which bestows on that order not only cognitive validity but normative legitimacy as well. Socialization involves the simultaneous transmission of knowledge and values. All understandings of the social world carry with them evaluations. Berger and Luckmann's position rejects the standard distinction between the explanation and evaluation of the social world. Presentation of traditional images, such as those of a gendered division of labor, legitimates that institutional order.

Viewed together, social constructionism and cultivation theory clearly suggest an approach to attracting more women to STEM careers. The strategy is to vastly increase media representation of women in these occupations. This should be undertaken in all varieties of programming including children's shows, dramas, situation comedies, talk shows, soap operas, and even commercials. The goal is to cultivate a social understanding of middle and high school girls enrolled in STEM classes, of women scientists, engineers, and technical experts as simply part of the natural social order - as nothing unusual. STEM education and careers can be presented as legitimate spheres of participation for women -- areas of professional activity in which women not only do but should participate.

Positive images of women technology professionals should not necessarily be images of bright, articulate, personable, physically attractive people. Certainly, they should not be less attractive than the other characters with whom they interact or than others who appear regularly on other programs. The important point is that women technology professionals appear frequently in the full variety of television programs. Young women should be commonly encountered as characters enrolled in technology-rich classes rebuilding computers.

It is important to note that women are not a monolithic group and, consequently, no one approach will work for attracting women to STEM disciplines. In addition to gender, other factors such as race, class, ethnicity, and sexual orientation influence education and career choices. ${ }^{13}$ This suggests that if a media strategy is to be helpful, it must involve diverse programming appealing to audiences composed of women with diverse demographic characteristics.

Women should be commonly encountered as characters competently doing technologically sophisticated work that is just as legitimately "woman's work" as it is "man's work." This proposal is consistent with research concluding that, at least in the United States, media routinely ignore and/or trivialize women's participation in STEM, and thereby discourage their career aspirations in scientific and technical fields. ${ }^{14,15}$

\section{The Pilot Study}

The preceding suggests the hypothesis that television viewers who have encountered images of women technical professionals are more likely to believe that STEM careers are acceptable (legitimate) careers for women than are those who have not seen such presentations. An opportunity presented itself to conduct a pilot study that, though limited in several ways, does 
shed some new light on the tenability of this suggestion.

Between April 1 and May 15, 2004, the Survey Research Institute at Purdue University conducted as a graduate student training exercise one of its periodic social surveys of the entire continental United States via a computer assisted telephone-interviewing (CATI) system. In the system, telephone numbers are selected randomly from a list of random digit dialing telephone numbers that include all area codes and telephone prefixes throughout the United States. The CATI system allows graduate student interviewers to record responses into a database while conducting the interview. CATI software prevents a researcher from calling anywhere in the United States before 9:00 a.m. or after 9:00 p.m. in each time zone.

For each potential interview, the respondent is first asked if he or she is 18 or not. If the respondent is not 18 or older, the researcher asks if anyone in the house is at least 18 years of age. Once an 18 year old is contacted, the respondent is asked if he or she has enough time to answer the survey. As long as the respondent agrees, the survey is administered. Should a respondent show an interest in taking the survey but state that he or she does not have the time to take the survey, a better time is scheduled in the CATI system and the respondent is called back at the rescheduled time. Upon completion of the interview, the researcher records the sex of each respondent. In the case that a respondent prematurely terminates the interview, all of the responses up to that point are saved and a callback is scheduled in an attempt to complete the interview.

Four hundred interviews were initiated of which 284 were completed for a response rate of 71 percent. The social survey allocated 30 minutes for questions of the pilot study investigating media images of women technology professionals. Three categories of STEM careers were selected to represent a broad range of specific professions: engineer, research scientist, and computer technician. The analysis dealt with the proportion of the sample that had seen actresses playing these occupational roles, an indirect measure of the relative attractiveness of those occupations, and the differences in attitudes toward the acceptability (legitimacy) of various careers for women between those who had and those who had not seen actresses playing those occupational roles on television.

\section{Limitations}

Although the sample did randomly include individuals representing a wide range of demographic characteristics, it cannot be considered representative of the entire population of the continental United States. Women, in particular, were over represented: 201(70.7 percent) as opposed to 83 (29.2 percent) male respondents. Since use of the CATI system prevented interviewing young women and men below the age of 18, high school students are not represented in the sample. Also, due to the necessary brevity and other characteristics of telephone surveys, respondents were asked short questions, some of which were only proxy measures of central concepts, such as the relative attractiveness of women in various STEM occupations, and the terms for those occupations such as "computer technician," which was used to represent a variety of computingfocused careers. The cumulative effect of encountering numerous positive images over time, central to cultivation theory, could not be explored. 


\section{Findings}

Data in Table 1 show that over 90 percent of the sample had seen actresses portray nurses, medical doctors, lawyers, and secretaries. This is not surprising in light of the long-term popularity of medical and legal dramas on United States prime time television. Female secretaries are likely to appear in work contexts in most varieties of television programming.

There is a considerable gap between the frequency with which respondents report seeing actresses portraying those roles and the frequency with which they report seeing actresses portraying other occupational roles, including three technology roles selected to represent a large cluster of related occupations: research scientist, computer technician, and engineer. Research scientists are seen much more frequently than are computer technicians and engineers. This probably reflects their appearances on several types of television dramas including crime, law, mystery, and science fiction. The only two occupational roles in which the majority of respondents had not seen actresses were computer technician and engineer. This is certainly due, at least in part, to the comparative rarity that such roles appear in any variety of programming. When decisions are being made as to the careers to assign female characters in television comedies, dramas, soap operas, and even commercials, having those characters portrayed as engineers or computer technicians would take advantage of a particular opportunity to establish women in technology as a part of the natural order of things.

Table 1

Question: Would you tell me if you have ever seen actresses on television playing characters with the following professions? (In percents)

\begin{tabular}{|l|c|c|}
\hline & Yes & No \\
\hline Nurse & 96.1 & 3.9 \\
\hline Medical Doctor & 93.0 & 7.0 \\
\hline Lawyer & 91.2 & 8.8 \\
\hline Secretary & 90.1 & 9.9 \\
\hline Research Scientist & 78.2 & 21.8 \\
\hline Factory Worker & 65.8 & 34.2 \\
\hline Elementary School Teacher & 63.7 & 36.3 \\
\hline Engineer & 50.6 & 49.4 \\
\hline Computer Technician & 44.7 & 55.3 \\
\hline
\end{tabular}


How attractive are women technology professionals compared to women in other occupations? Elementary school teacher was selected as the profession for comparison. This is one of the most traditional middle-class occupations, and has had a long history of being gender stereotyped as appropriate for women. Data in Table 2 below indicate that the relative attractiveness of women in technology generally is a reflection of the standing of their occupation in the occupational prestige hierarchy. However, there are exceptions. When comparing respondent perceptions of the attractiveness of a woman who is an engineer or a research scientist with that of a woman who is an elementary school teacher, the latter is more frequently judged more attractive. Generally, engineers and research scientists have more education, higher income, and higher occupational prestige than elementary school teachers. Yet, data show that respondents believed most men would prefer an elementary school teacher as a spouse or partner. Such a finding indicates the need to improve the image of women in technology-rich professions.

Table 2

Question: I would like you to tell me which of two women, described by their careers, do you think most men would prefer as a spouse or partner? (In percents)

\begin{tabular}{|l|l|l|}
\hline & & $\begin{array}{l}\text { Elementary } \\
\text { School Teacher }\end{array}$ \\
\hline Medical Doctor & 64.4 & 35.6 \\
\hline Nurse & 61.3 & 38.7 \\
\hline Lawyer & 49.6 & 50.4 \\
\hline Engineer & 44.2 & 55.8 \\
\hline Research Scientist & 39.1 & 60.9 \\
\hline Computer Technician & 28.2 & 71.8 \\
\hline Secretary & 24.6 & 75.3 \\
\hline Factory Worker & 14.1 & 85.9 \\
\hline
\end{tabular}

$\mathrm{n}=284$

Are those who have seen actresses in a STEM occupation significantly more likely than others to believe it is an acceptable (legitimate) occupation for a woman? The answer to this question bears directly on the tenability of the theoretical assumption central to this paper: Media images of social reality come to be regarded not only as the empirical but also as the normative "natural order of things." 
Respondents were asked the extent to which they agreed with the statement that each of several STEM careers (research scientist, engineer, computer technician) was an "acceptable career for a woman." The theoretical expectation is that those respondents who had seen an actress on television playing the role of a technology professional would more frequently report that the role is legitimate for a woman than those who indicated they had never seen such a representation. Because attitudes of men and women toward women in technology might be quite different, their responses also were analyzed separately.

In the case of each of the three careers, five comparisons were made: overall between the attitudes of those who had and those who had not seen a representation of a woman in that occupational role on television, between men who had seen and men who had not seen such a portrayal, between women who had seen and women who had not seen such a portrayal, between men who had and women who had seen such a portrayal, and between men who had not seen and women who had not seen such a portrayal.

Data in Table 3 were used to calculate the magnitude of difference in the distribution of attitudes for the overall sample. Chi square tests were used to assess the probability that the magnitude of each of the observed differences was due to chance. Due to space limitations, data used to calculate additional chi square values are not presented here. However, they are available from the author. Chi square tests require row and column totals greater than zero. Consequently, in some tables, strongly disagree and even disagree responses were eliminated in the calculation.

Table 3

Question: Do you agree or disagree: Is it acceptable for a woman to be a research scientist?

\begin{tabular}{|c|c|c|c|c|c|c|}
\hline Saw & $\begin{array}{c}\text { Strongly } \\
\text { Disagree }\end{array}$ & Disagree & Uncertain & Agree & $\begin{array}{c}\text { Strongly } \\
\text { Agree }\end{array}$ & Total \\
\hline Yes & 0 & 13 & 20 & 92 & 97 & 222 \\
\hline No & 0 & 0 & 4 & 29 & 29 & 62 \\
\hline
\end{tabular}

Chi Square Values for Comparisons

\author{
$P$ value \\ (.05 or less)
}
a. Overall yes vs. overall no
0.25
ns
b. Men yes vs. men no
0.74
ns
c. Women yes vs. women no
0.34
ns
d. Men yes vs. women yes
0.14
ns
e. Men no vs. women no
0.70
ns 
None of the comparisons using the data in Table 3 reveals a statistically significant difference between the attitudes of those who had and those who had not seen an actress portray a research scientist on television. In the case of research scientists, data do not conform to the theoretical expectation.

Data in Table 4 present similar results. None of the five comparisons reveals a statistically significant difference. In the case of engineers, as in the case of research scientists, data do not conform to the theoretical expectations.

Table 4

Question: Do you agree or disagree: Is it acceptable for a woman to be an engineer?

\begin{tabular}{|c|c|c|c|c|c|c|}
\hline Saw & $\begin{array}{c}\text { Strongly } \\
\text { Disagree }\end{array}$ & Disagree & Uncertain & Agree & $\begin{array}{c}\text { Strongly } \\
\text { Agree }\end{array}$ & Total \\
\hline Yes & 0 & 2 & 3 & 51 & 66 & 122 \\
\hline No & 0 & 5 & 14 & 72 & 71 & 162 \\
\hline
\end{tabular}

$\mathrm{n}=284$

Chi Square Values for Comparisons

$\mathrm{P}$ value

(.05 or less)
a. Overall yes vs. overall no
0.20
ns
b. Men yes vs. men no
0.21
ns
c. Women yes vs. women no
0.31
ns
d. Men yes vs. women yes
0.43
ns
e. Men no vs. women no
0.37
ns

Data in Table 5, however, tell a different story. Table 1 showed that fewer viewers had seen an actress on television playing a computer technician than playing any one of the eight other professional roles considered in this study. Table 2 indicated that overall, women who are computer technicians are much less frequently viewed as attractive than are women who are engineers or research scientists. Table 5 shows that overall, of the 284 respondents, the majority (53.2 percent) disagreed with the statement that it is acceptable for a woman to be a computer technician. This is an impressive statistic when contrasted with the corresponding 4.6 percent for research scientist and 2.5 percent for engineer. If there is a need to create a more positive view of women technology professionals, computer technicians would appear to be among those in greatest need. 
Table 5

Question: Do you agree or disagree: Is it acceptable for a woman to be an computer technician?

\begin{tabular}{|c|c|c|c|c|c|c|}
\hline Saw & $\begin{array}{c}\text { Strongly } \\
\text { Disagree }\end{array}$ & Disagree & Uncertain & Agree & $\begin{array}{c}\text { Strongly } \\
\text { Agree }\end{array}$ & Total \\
\hline Yes & 25 & 32 & 6 & 37 & 27 & 127 \\
\hline No & 54 & 40 & 12 & 33 & 18 & 157 \\
\hline
\end{tabular}

Chi Square Values for Comparisons

$\mathrm{P}$ value (.05 or less)
a. Overall yes vs. overall no
$9.90 \mathrm{E}-22$
$<.001$
b. Men yes vs. men no
0.43
ns
c. Women yes vs. women no
0.05
$<.05$
d. Men yes vs. women yes
$1.42 \mathrm{E}-10$
$<.001$
e. Men no vs. women no
$5.18 \mathrm{E}-14$
$<.001$

Consistent with theoretical expectations, overall differences in the attitudes of those who saw an actress portray a computer technician and those who did not are statistically significant. Corresponding differences also were found for women but not for men. Significant differences were found between the attitudes of men and women all of whom had seen a portrayal and between men and women, all of whom had not seen a portrayal. These results indicate the existence of gender differences in attitudes toward computer technicians (and perhaps toward other STEM occupations as well) and in the apparent ability of media representations to influence perceptions of and attitudes toward women in certain STEM careers. If more women are to be attracted to STEM occupations, it would seem important to influence the perceptions and attitudes of men as well as those of women. It is primarily men who teach classes in STEM disciplines in high schools and colleges, make admission decisions to college and university science, engineering, and technology programs, hire scientists, engineers, and other technology professionals, and constitute the majority of colleagues with whom women work in these professions.

\section{Discussion and Conclusion}

Part of the solution to the shortage of trained scientists, engineers, and computer professionals in 
advanced industrial societies is to attract more women to careers in these areas. One widely discussed strategy for accomplishing this goal is to make such careers more attractive through the use of the media, particularly television. While this proposal makes common sense, several questions have yet to be addressed. These are the concerns of this paper. Are there sound reasons to believe that a media-centered approach will achieve some success? That is, what is the theoretical basis for the hypothesis that exposure to positive television images of women as technology professionals will attract more of them to STEM careers? What causal mechanism is involved? Understanding causal dynamics can inform actions taken to produce desired results. What will empirical data suggest about the tenability of the hypothesis? Can we move beyond common sense and anecdotal evidence in evaluating the hypothesis?

The works of social theorists Alfred Schutz, Peter Berger, and communication researcher George Gerbner provide an explanation for our understanding, evaluation, and reaction to the social world. Commonly encountered representations of actors, conditions, and events in the "real world" come to be understood, correctly or not, as the nature of reality itself. Furthermore, this understanding of the "natural order of things" comes to be accepted as the proper or legitimate structure. Such an understanding provides a guide for social behavior. The theory suggests that if children seldom or never encounter, directly or indirectly through the media, girls in laboratory classes or solving difficult mathematics problems, they are likely to believe that such educational pursuits are naturally the purview of boys. Similarly, if adults seldom or never encounter, directly or indirectly through the media, women scientists, engineers, or technicians, they are likely to believe that such careers are "naturally" careers for men.

The social construction of reality perspective and cultivation theory suggest a strategy for attracting more women to STEM careers: use media to present the public continuously with images of women in a wide variety of technology-rich educational programs and occupations. The object is to cultivate the view of women scientists, engineers, mathematicians, and technology professionals, and of young women preparing for those careers, as nothing exceptional. The goal is to construct the socially shared perspective that it is just as "natural" for a woman to be a STEM professional as it is for her to be a medical doctor or a lawyer.

Social constructionism and cultivation theory call attention to the importance of the frequency with which audiences encounter positive media images women technology professionals. To reach large and diverse audiences, representations must appear in a wide range of television program formats including soap operas, situation comedies, talk shows, dramas, commercials, and arguably most important of all, programs that appeal to teenage girls. It is helpful to produce programs that feature strong, competent and otherwise attractive female characters in the role of technology professionals. However, for the most part, positive images of women in technology need not be glamorous images. Primarily producing such images might actually discourage women whose self-assessments are not nearly so glamorous from pursuing STEM careers.

This pilot study investigated the tenability of one of two hypotheses derived from social theory and communication research. The first hypothesis states that those who have been exposed to positive media images of women technology professionals are more likely to believe that STEM careers are legitimate careers for women than are those who have not been exposed to such images. The second hypothesis states that widespread belief that STEM careers are legitimate careers for women will actually move more women to those careers. Investigating this second 
hypothesis is beyond the scope of this pilot study.

As noted earlier, although data were drawn randomly from the entire population of the continental United States, the sample was too small to be considered representative of the entire country. They certainly cannot be taken as representative of the views of those in other nations as well. Also previously noted, the necessary brevity and other characteristics of telephone surveys imposed further limitations. The cumulative effect of encountering numerous positive images over time, central to cultivation theory, could not be explored. However, while findings are tentative, they are suggestive. Among these are:

1. There may be vast differences in the frequency with which television audiences have encountered representations of women in different STEM occupations.

2. There may be vast differences in public perceptions of the relative attractiveness of various technology-rich occupations.

3. In each of the cases of research scientist, engineer, and computer technician, men were more likely than women to agree that the profession is an acceptable career for a woman. This is encouraging, since, as noted, those hiring women into these positions and serving as faculty in their university courses are more likely to be men than women.

4. Exposure to positive images of women in technology may increase the likelihood that viewers will believe these are acceptable careers for women in the case of some STEM careers (e.g., computer technician) but not others (e.g., research scientist and engineer.)

5. Significantly fewer women than men believe that the computing category of STEM career represented by computer technician is acceptable for women. It might be more profitable to invest more effort in creating positive media images of women in computerfocused careers.

Computer technician emerged from the pilot study as the career category deemed least acceptable to both men and women as being appropriate for a women. Fewer viewers surveyed had seen an actress on television playing a computer technician than playing any one of the eight other professional roles considered in this study. Women who are computer technicians were viewed as less attractive than women in other STEM careers.

Additional research, using a representative sample of the United States, more rigorously defined concepts, and more sensitive measures is needed to determine whether or not these findings of the pilot study, tentatively suggesting that the media strategy most likely to be effective is one targeting young women likely to be interested in becoming computer technicians, are, in fact, valid. Future research should also include respondents under the age of 18 , because it can be useful to know the views of students preparing to select their future professions. The impact of variables such as age, race, and class would also be instructive.

Similar international data are needed to determine whether or not the findings would apply in other countries as well. The findings can be understood as suggesting patterns of beliefs, values, and their sources likely to be found in the country as a whole. If the findings hold, it would appear that the majority both men and women find other STEM careers appropriate for women, suggesting that a media strategy would be less effective in raising those numbers, and that other explanations and strategies should be explored. 


\section{REFERENCES}

1. Mervis, J. (2000). Diversity: Easier said than done. Science, 289 (5478), 378-379.

2. AAUW. (2000). Tech-savvy: Educating girls in the new computer age. Washington, DC: AAUW Educational Foundation.

3. Femtec. (2002). Introduction to Femtec: University-based career center for women Berlin, Inc. Berlin, Germany: Femtec.

4. Charles, M., \& Bradley, K. (2005). Women and information technology: Research on the reasons for under representation. Paper presented at the $100^{\text {th }}$ Annual Meeting of the American Sociological Association, Philadelphia, PA, August 13.

5. Seymour, E. (1999). The role of socialization in shaping the career-related choices of undergraduate women in science, mathematics, and engineering majors. In C.C. Selby (Ed.), Women in science and engineering: Choices for success (pp. 118-126). New York: The New York Academy of Sciences.

6. National Science Foundation. (2003). New formulas for America's workforce: Girls in science and engineering. Washington, DC: National Science Foundation.

7. Freeman, C. E. (2004). Trends in educational equity of girls \& women: 2004 (No. NCES 2005-016). Washington, DC: U.S. Government Printing Office: U.S. Department of Education, National Center for Education Statistics.

8. Huang, G., Taddese, N., \& Walter, E. (2000). Entry and persistence of women and minorities in college science and engineering. (No. NCES 2001-601). U.S. Department of Education National Center for Education Statistics. Washington, DC: U. S. Government Printing Office.

9. National Council for Research on Women. (2001). Balancing the equation: Where are the women and girls in science, engineering, and technology? New York: National Council for Research on Women..

10. Schutz, A. (1932/1967). The phenomenology of the social world. Evanston, IL: Northwestern University Press.

11. Berger, P. L., \& Luckmann, T. (1966). The social construction of reality: A treatise in the sociology of knowledge. Garden City, NY: Anchor Books.

12. Gerbner, G. (1976). Television and its viewers: What social science sees. Santa Monica, CA: Rand Corporation.

13. Rosser, S. V. (1998). Applying feminist theories to women in science programs. Signs, 24, 174-202.

14. Potts, R., \& Martinez, I. (1994). Television viewing and children's beliefs about scientists. Journal of Applied Development Psychology, 15, 287-300.

15. Steinke, J. (1997). A portrait of a woman as a scientist: Breaking down barriers erected by gender role stereotypes. Public Understanding of Science, 6, 409-428. 